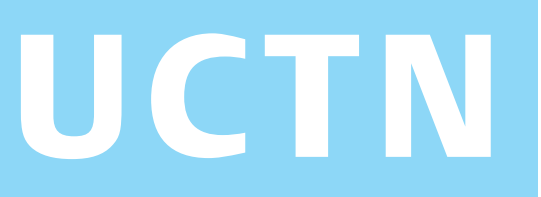

A 29-year-old man presented with a 3month history of dysphagia and chest pain. Esophagogastroduodenoscopy showed a narrowed mid-esophagus with smooth mucosa (Figure 1). Endoscopic ultrasound (EUS) was performed, which showed loss of echo layers, esophageal wall thickening (Figure 2), and enlarged mediastinal lymph nodes (Figure 3). EUSguided fine-needle aspiration (FNA) of these lymph nodes was not performed at this stage because the patient was agitated. Endoscopic biopsies from the midesophagus showed eosinophilic esophagitis with $>15$ eosinophils per high-power field. He was treated with Advair (fluticasone/salmeterol) for 1 month by his physician and the dysphagia resolved.

Repeat esophagogastroduodenoscopy and EUS-FNA under monitored anesthetic care showed no esophageal luminal narrowing and significant reduction in the thickness of the esophageal wall (Figure 4). Enlarged subcarinal lymph nodes $(15 \mathrm{~mm}$ and $27 \mathrm{~mm}$ ) were seen once again. EUS-FNA of the larger lymph node (Figure 5) revealed polymorphic, smalllymphocytic proliferation, and numerous eosinophils, with a cytologic pattern that was most consistent with reactive lymph-node hyperplasia with eosinophilia (Figure 6). No granuloma, Reed-Sternberg cells, metastasis, or evidence of lymphoma was identified.

There have been few case reports describing the EUS findings in esophageal eosinophilia [1-3]. Fox et al. [1], performed high-resolution EUS on 11 children with esophageal eosinophilia and eight controls and found significant differences in wall thickness. Evrard et al. [2] described a 72-year-old man with dysphagia and weight loss, in whom EUS showed a localized infiltrating process between the muscular layers. He underwent esophagectomy because he was suspected to have a neoplasm, and was revealed to have esophageal eosinophilia. Stevoff et al. [3] described an 85-year-old man with an esophageal stricture, normal mucosa,

\title{
Endoscopic ultrasound-guided fine-needle aspiration of enlarged mediastinal lymph nodes in eosinophilic esophagitis
}

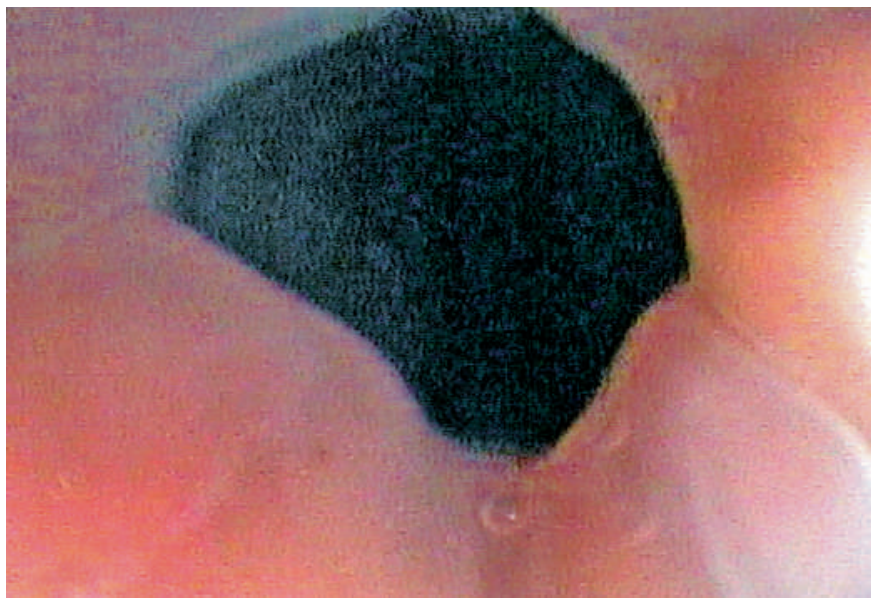

Figure 1 Endoscopic view of smooth, normal-appearing mucosa in the mid-esophagus, with luminal narrowing. The endoscopic biopsies revealed eosinophilic esophagitis.

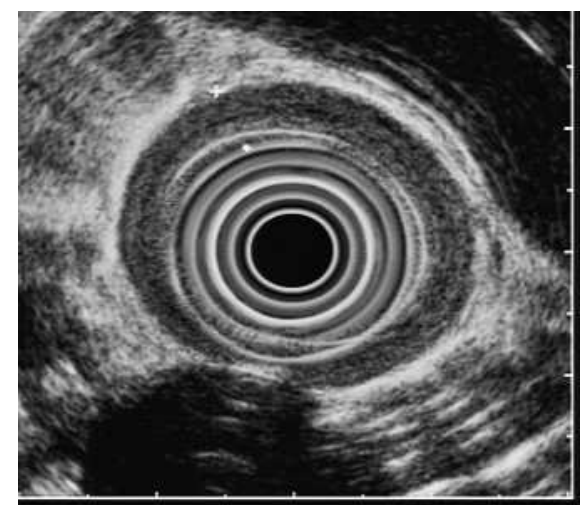

Figure 2 Radial endoscopic ultrasound (EUS) in the mid-esophagus, showing a thickened esophageal wall with loss of the echo layer pattern.

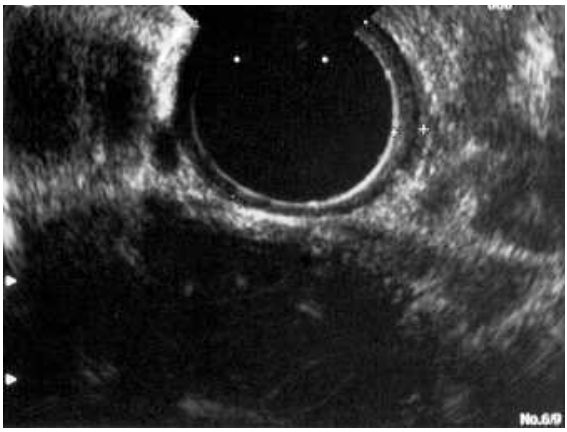

Figure 4 Radial EUS after treatment of the eosinophilic esophagitis, showing a decrease in the thickness of the esophageal wall.

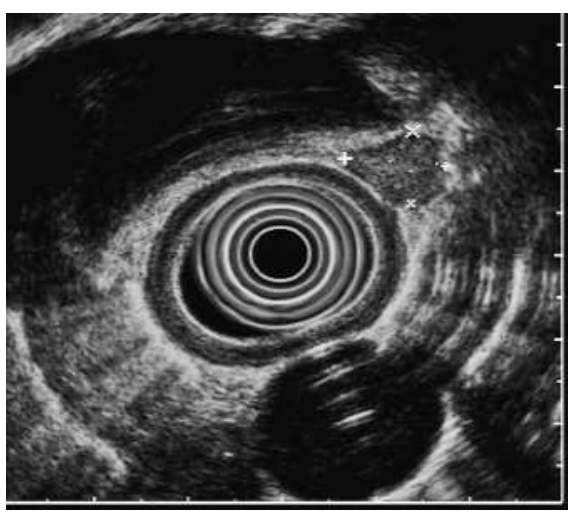

Figure 3 Radial EUS showing an enlarged mediastinal lymph node.

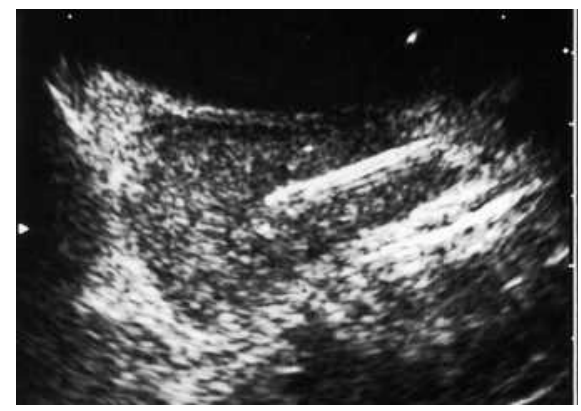

Figure 5 Linear EUS with fine-needle aspiration (FNA) of an enlarged mediastinal lymph node. 
and circumferential thickening of the muscularis propria on EUS. Esophagectomy was performed because atypical cells had been identified in the fine-needle aspirate, and this revealed esophageal eosinophilic infiltration involving the muscularis propria on pathologic examination. Our patient's biopsies were consistent with a diagnosis of esophageal eosinophilia. Esophageal thickening was noted, along with loss of the echo layer pattern and this subsequently resolved. The presence of eosinophils in the mediastinal lymph nodes on EUS-FNA in association with esophageal eosinophilia in our case is very interesting and to our knowledge has not been reported previously.

Endoscopy_UCTN_Code_CCL_1AB_2AC_3AD

Endoscopy_UCTN_Code_CCL_1AF_2AC

M. S. Bhutani' ${ }^{1}$ B. Moparty ${ }^{1}$, C. T. Chaya ${ }^{1}$, V. Schnadig', R. Logrono ${ }^{2}$

${ }^{1}$ Center for Endoscopic Ultrasound and CERTAIN (Center for Endoscopic Research, Training and Innovation), University of Texas Medical Branch, Galveston, Texas, USA

2 Department of Cytopathology, University of Texas Medical Branch, Galveston, Texas, USA.
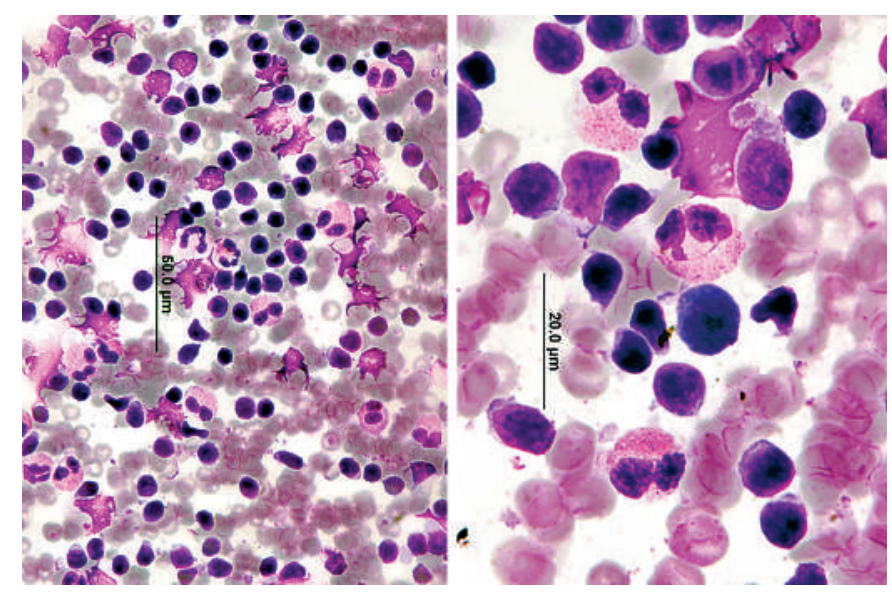

Figure 6 Mediumand high-power views of the aspirate obtained by transesophageal EUS-FNA of the mediastinal lymph node shown in Figure 5. Several eosinophils are seen admixed with lymphoid tissue, which is mainly composed of small lymphocytes. A few large lymphocytes are also present (Romanowski stain [Quik Dip]).

\section{References}

${ }^{1}$ Fox VL, Nurko S, Teitelbaum JE et al. High-resolution EUS in children with eosinophilic "allergic" esophagitis. Gastrointest Endosc 2003; 57: 30-36

${ }^{2}$ Evrard S, Louis H, Kahaleh M et al. Idiopathic eosinophilic oesophagitis: atypical presentation of a rare disease. Acta Gastroenterol Belg 2004; 67: 232 - 235

${ }^{3}$ Stevoff C, Rao S, Parsons W et al. EUS and histopathologic correlates in eosinophilic esophagitis. Gastrointest Endosc 2001; 54: 373-377

\section{Corresponding author}

\section{S. Bhutani, MD}

Center for Endoscopic Ultrasound University of Texas Medical Branch 301 University Blvd., Route 0764

Galveston

Texas 77555-0764

USA

Fax: $\quad+1-409-772-4789$

Email: msbhutan@utmb.edu 